\title{
The Relationship Between Amplification And Quality Factors of Seismic Waves In Surface Sediment Layer
}

\author{
Cahya Damayanti ${ }^{1}$, Sismanto $^{2}$ \\ \{cahy009@lipi.com ${ }^{1}$, cakra.cahya@gmail.com²\}
}

${ }^{1}$ Deep Sea Research Center, Indonesian Institute of Sciences (LIPI), Poka, Ambon, Indonesia

${ }^{2}$ Department of Physics, Gajah Mada University, Sekip Utara Bulaksumur, Yogyakarta, Indonesia

\begin{abstract}
This research was conducted to identify amplification and attenuation that occur in the soft sediment layer. The softer a surface sediment layer, the greater the amplification value so that the amplitude of the propagating wave will be even greater. This causes the softer surface sediment layer, the value of the wave propagation quality factor is also greater. This data is processed using the HVSR method with 94 data points. The results of this study indicate that the amplification value has a linear relationship with the quality factor owned and inversely proportional to the attenuation.
\end{abstract}

Keywords: Surface, Sediment, Seismic.

\section{Introduction}

Solok has high seismic vulnerability index as passed by the Sumatra fault segment is segment Sumani and Sianok. When an earthquake occurs, not infrequently cause damage. Damage caused by an earthquake regions do not only depend on regional distancesto the epicenter and the magnitude of the earthquake but also depends on surface geological conditions (surface sedimentary layer) area. Soft surface sedimentary conditions cause the area to experience a greater damage effect compared to hard rocky conditions [1].

Microtremor is a constant vibration on the surface of the earth which is very weak with amplitudes between 10-4-10-2 mm. Source microtremor comes from human activity such as industrial machinery, traffic and activities natural phenomena such as river water flow, wind, variations in atmospheric pressure, ocean waves [12].

Mikrotremor measurements can be used to determine the geological conditions of the soil covering the dynamics of soil characteristics in the form of dominant frequency, amplification, quality factor, a secondary wave velocity and thickness of the surface sediment layer. In this study a theoretical study was carried out and microtremor data analysis using HVSR method for determining relationships seismic wave amplification (amplification value HVSR curve) with wave attenuation seismic (value of wave propagation quality factor seismic) in surface sedimentary layers.

Amplification is a magnification of seismic waves that occur due to significant differences between layers. Amplification will occur when the earthquake wave frequency values are the samen with the resonance frequency of the surface sediment layer [11].

Quality factor states the ratio between the energy that enters the medium and the energy absorbed.

\section{Method}

Energy seismic waves that pass through a medium will experience absorption by the medium because it is converted into heat generated from medium particle friction move when crossed 
by seismic waves [9]. Process this energy absorption is called wave attenuation which results in decreased amplitude the wave and its value depend on the type of medium which is stated in a constant attenuation [4]. On the medium soft the attenuation constant value is getting large so the wave amplitude will weakened. This is the opposite of the peda effect surface that occurs in the surface layer where the waves will experience amplification / magnification when an earthquake occurs.

Research put forward by Nakamura which states that the comparison of the spectrum as a function of frequency is closely related to the function of the transfer site [5]. The amplification factor of the horizontal and vertical components on the surface of the soil in direct contact with the bedrock in the area of the basin is denoted by TH and TV [7]. The magnitude of the amplification factor is horizontal $\mathrm{TH}$.

$$
T_{H}=\frac{S_{H S}}{S_{H B}}
$$

Nakamura also shows that the ratio between the horizontal and vertical components of the recording of the ambient noise is closely related to the dominant frequency of the ground and from here obtained amplification factor [6].



Fig. 1. Example of spectrum analysis results HVSR

The relationship between the quality factor $(\mathrm{Q})$ and the dominant frequency resonance occurs when expressed in the equation of [4], namely (2).

$$
\frac{1}{Q}=\frac{2 \Delta f}{f_{0}}
$$

With $2 \Delta f$ is wide bandwidth / frequency band which is the width of the resonance curve on the amplitude of 0.707 of its peak value (Figure 2 ). 


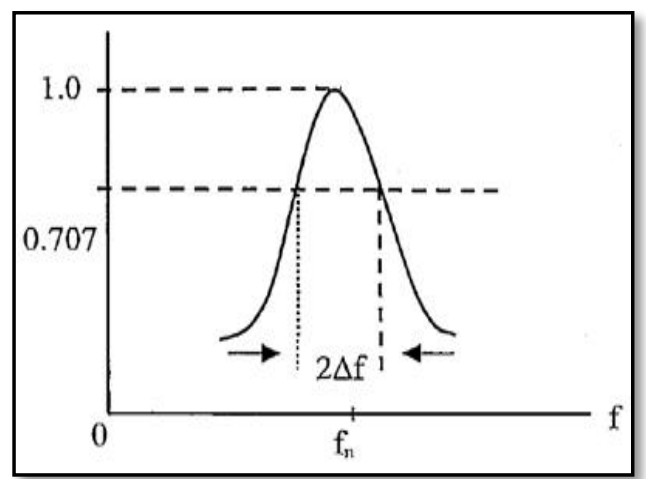

Fig. 2. curve and the relationship between the resonance frequency shift of the resonance frequency [4].

At the resonant frequency, the earthquake wave of bedrock will be magnified $\mathrm{A}$ times (A is the value of amplification) in the surface sediment layer so that the amplitude of the wave of earthquakes in the surface sediment layer can be expressed as (3).

$$
a_{S}=A a_{B}
$$

According to Nakamura (2000) [7], amplification value expressed by equation (4).

$$
A=\frac{\rho_{B} V_{S B}}{\rho_{S} V_{S S}}
$$

The amplitude [9] of waves that pass a certain layer thickness will experience the energy absorption by the medium so that the amplitude will be reduced to equations (5).

$$
a=a_{0} \exp (-\alpha h)
$$

While the relationship between the quality factor $(\mathrm{Q})$ with the attenuation constant is expressed as the equation (6).

$$
Q=\frac{\pi f}{\alpha V}
$$

Thus equation (2) and (3) can be expressed in the equation (7).

$$
a=a_{0} \exp \left(-\frac{\pi f h}{Q V_{s}}\right)
$$

\section{Result}

Solok consists of sedimentary rocks, metamorphic, volcanic and old alluvium permokarbon to resen. The oldest rocks in the form permocarbon aged metamorphic rocks. The metamorphic rocks intruded by granite intrusive rocks $(\mathrm{g})$ aged triad. Are aligned on top of these rocks deposited sedimentary rock Tertiary age. Quarter-lived volcanic rocks deposited on top of older rocks. Resen old youngest rocks in the form of alluvium (Qal) [10]. Single station microtremor measurements of 86 sites (figure 3 ) used Mark L4-3D seismometer were carried out over solok city and its vicinity from April to Mei 2015. 




Fig. 3. Distribution of measurement points

The HVSR method has been applied on data that were acquired, selected, processed according to the recommendations of Sesame European Project and computed using geopsy free software. Before the spectra computation, the window length for each data was set to a period of 15 seconds in order to capture low frequency of $\mathrm{H} / \mathrm{V}$ peak curve at a sampling rate of 100 samples per second and 5\% cosine taper value. Geopsy software were used to compute the mean and linear trend of all windows, then transformed into Fourier spectra and smoothed by Konno and Ohmachi one with $b=15$.

The result of the calculation of the quality factor then compared with the value of amplification by creating graphs crossplot between amplification by a factor of quality can be seen in Figure 5.1 .

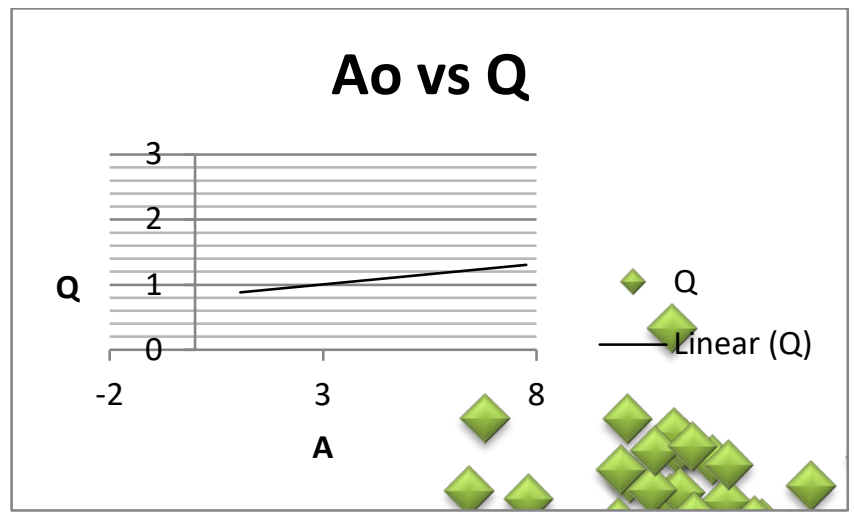

Fig. 4. Graph of crossplot amplification values and quality factor

The graph shows the relationship between amplification and quality factors is proportional.The results illustrate the quality factor value processing sedimentary soil surface. The more soft a surface sediment layer then the value will be even greater amplification so that the amplitude of the wave which propagates will be even greater. This causes more soft sedimentary layers of the surface wave propagation factor value greater quality. The results of the quality factor is only used as additional information in the discussion of the value of the seismic vulnerability 
index. The distribution of amplification values in the study area can be seen in Figure 5 with amplification values ranging from 1.5-6.3. Amplification expresses the contrast impedance between the surface sediment layer and the bedrock layer below. So that the difference in the amplification value on the same surface geology can be caused by variations in the bedrock layer in the study area.

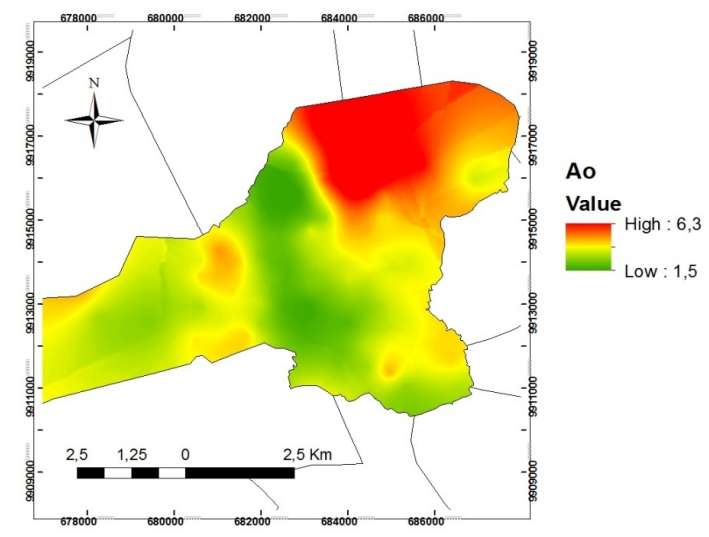

Fig. 5. Amplification Map

The value of quality factors in this study area ranged from 0.6 to 1.4 Regions that have the largest quality factors are in the northeast and west, this area is the same as the distribution of the amplification values.

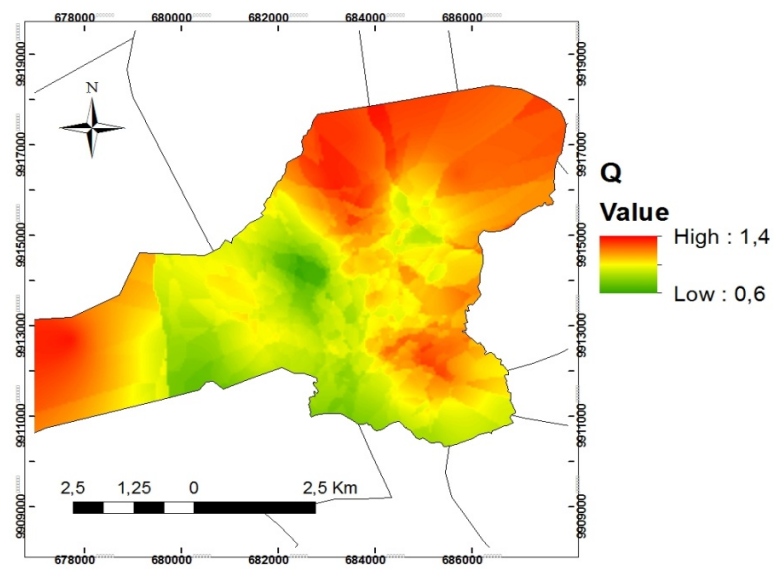

Fig. 6. Quality Factor Map

Based on the results of this study, then the quality factor obtained from the curve HVSR on this research is a quality factor secondary wave propagation. More and more then a soft layer of surface sediment the amplification value will be greater so that the amplitude of the radiating wave will the greater it is. This causes increasingly soft layer of surface sediment hence the value the wave propagation quality factor the greater it is. Areas that have amplification values and high quality factors will suffered severe damage during an earthquake. 


\section{Conclusion}

The relationship between the amplification (A) with a quality factor (Q) of the microtremor data in Solok is linear because when there is resonance, in a layer of sediment that is traversed by the earthquake waves will experience the amplification effect is more dominant than the effect of its attenuation.

\section{Acknowledgement.}

Pusat Survey Geologi (PSG) for the data that had been used in this research.

\section{References}

[1.]Gurler, E., Nakamura, Y., Saita, J. \& Tsutomu, 2000. Local Site Effect of Mexico City Based on Microtremor Measurement. California, USA, Proceeding of 6th International Conference of Seismic Zonation.

[2.]Isihara, K., 1982, Evaluatian of Soil Properties for Use in Earthquake Response Analysis. Proc. Int. Symp. On Numerical Model in Geomech, 237-259.

[3.]Kanai, K. 1966. Improved Empirical Formula for Characteristics of Stray (sic)

[4.]Earthquake Motions. Page 1-4 of: Proceedings of the Japanese Earthquake

[5.]Symposium. Not seen. Reported in Trifunac \& Brady (1975).

[6.]Munadi, S. 2000. Aspek Fisis Seismologi Eksplorasi, Program Studi Geofisika, Jurusan

[7.]Fisika, FMIPA, Universitas Indonesia, Depok.

[8.]Nakamura, Y. 1989. A Method for Dynamic Characteristic Estimation of Subsurface using Microtreor on the Ground Surface, QR Railway Technical Research Institute, 30, 1, 25-33.

[9.]Nakamura, Y, 1997, Seismic Vulnerability Indices for Ground And Structures Using Microtremor, World Congress on Railway Research. Florence, Nov. 1997.

[10.]Nakamura, Y., T. Sato, dan M. Nishinaga. 2000. Local Site Effect of Kobe Based on Microtremor Measurement. Proceeding of the Sixth International Conference on Seismic Zonation EERI, Palm Springs California.

[11.]Shelley, E.O., Javier L.S., Gabriel A., dan Edgar M.S. 2012. Microtremor Measurements To Identify Zones Of Potential Fissuring In The Basin Of Mexico, J. Geofisica Internacional, 51, 2, 143-156.

[12.]Sheriff, R.E., dan Lloyd P.G. 1995. Exploration Seismology; Second Edition, Cambridge University Press, London.

[13.]Silitonga, P.H dan Kastowo. 2007. Peta Geologi Lembar Solok. PPG, Bandung.

[14.]Seht, M. \& Wohlenberg, J., 1999. Microtremor Used To Map Thickness Of Soil. Bulletin of the Seismological Society of America, 89(1), pp. 250-259.

[15.]Okada, H., 2003. The Microtremor Survey Method (Geophysical Monograph Series Number 12), Amerika: Society of Exploration Geophysicists. 